\title{
Drugs for malaria: something old, something new, something borrowed
}

\author{
Charlotte Hobbs ${ }^{1}$ and Patrick Duffy ${ }^{2 *}$
}

Addresses: ${ }^{1}$ NIH/NIAID, Laboratory of Malaria Immunology and Vaccinology, 12735 Twinbrook Parkway, 3W19E, Rockville, MD 20852, USA; ${ }^{2}$ NIH/NIAID, Laboratory of Malaria Immunology and Vaccinology, Division of Intramural Research, 5640 Fishers Lane, Rm. 1111 Rockville, MD 20892, USA

*Corresponding author: Patrick Duffy (patrick.duffy@nih.gov)

FI000 Biology Reports 20II, 3:24 (doi:10.34I0/B3-24)

This is an open-access article distributed under the terms of the Creative Commons Attribution-Non Commercial License (http://creativecommons.org/licenses/by-nc/3.0/legalcode), which permits unrestricted use, distribution, and reproduction in any medium, provided the original work is properly cited. You may not use this work for commercial purposes.

The electronic version of this article is the complete one and can be found at: http://f1000.com/reports/b/3/24

\begin{abstract}
Malaria was estimated to cause 800,000 deaths and 225 million cases worldwide in 2010 . Worryingly, the first-line treatment currently relies on a single drug class called artemisinins, and there are signs that the parasite is becoming resistant to these drugs. The good news is that new technology has given us new approaches to drug discovery. New drugs generated this way are probably 10-15 years away from the clinic. Other antimalarials that may offer hope include those rehabilitated after not being used for some time, those that act as inhibitors of resistance mechanisms, those that limit infection while allowing protective immunity to develop, and those which are drugs borrowed from other disease treatments. All of these offer new hope of turning the tables on malaria. In parallel with the effort to develop vaccines that interrupt malaria transmission, drugs that target the parasite during transmission to the mosquito or during its pre-erythrocytic development in the liver, may allow us to terminate the parasite's spread.
\end{abstract}

\section{Introduction}

The World Health Organization (WHO) estimated 800,000 malaria deaths and 225 million cases worldwide in 2010 [1], with severe disease concentrated among young children and pregnant women [2]. Geographically, malaria overlaps with other infectious maladies including HIV, which often complicate the illness as well as treatment options. Worryingly, first-line treatment for malaria currently relies on a single drug class called artemisinins, and the existing drug armamentarium is insufficient to answer the call for malaria eradication. Under the circumstances, scientists are exploring many approaches, targeting different stages of the parasite life cycle, to find agents that will prevent, cure, or eliminate malaria. These approaches include new drug discovery, old drug rehabilitation, and drugs borrowed from other fields for use against malaria.

\section{Malaria parasites: many potential targets, few effective drugs \\ Malaria life cycle}

Human malaria is transmitted by the bite of female Anopheles mosquitoes that carry sporozoites (the motile infective stage of the parasite) in their salivary glands (Figure 1). Sporozoites inoculated into skin enter blood vessels and are carried to the liver, where they pass through Kupffer cells, invade hepatocytes, and multiply 10-thousand-fold over a week to form liver stage merozoites. Plasmodium vivax and Plasmodium ovale parasites that invade the liver may develop into a dormant form called hypnozoite that can cause relapse after months or years. These stages of infection, called the pre-erythrocytic (pre-blood) stages, are clinically silent. Liver stage merozoites released into the blood stream infect individual host red blood cells to initiate the erythrocytic (blood) 
Figure I. Life cycle of the malaria parasite

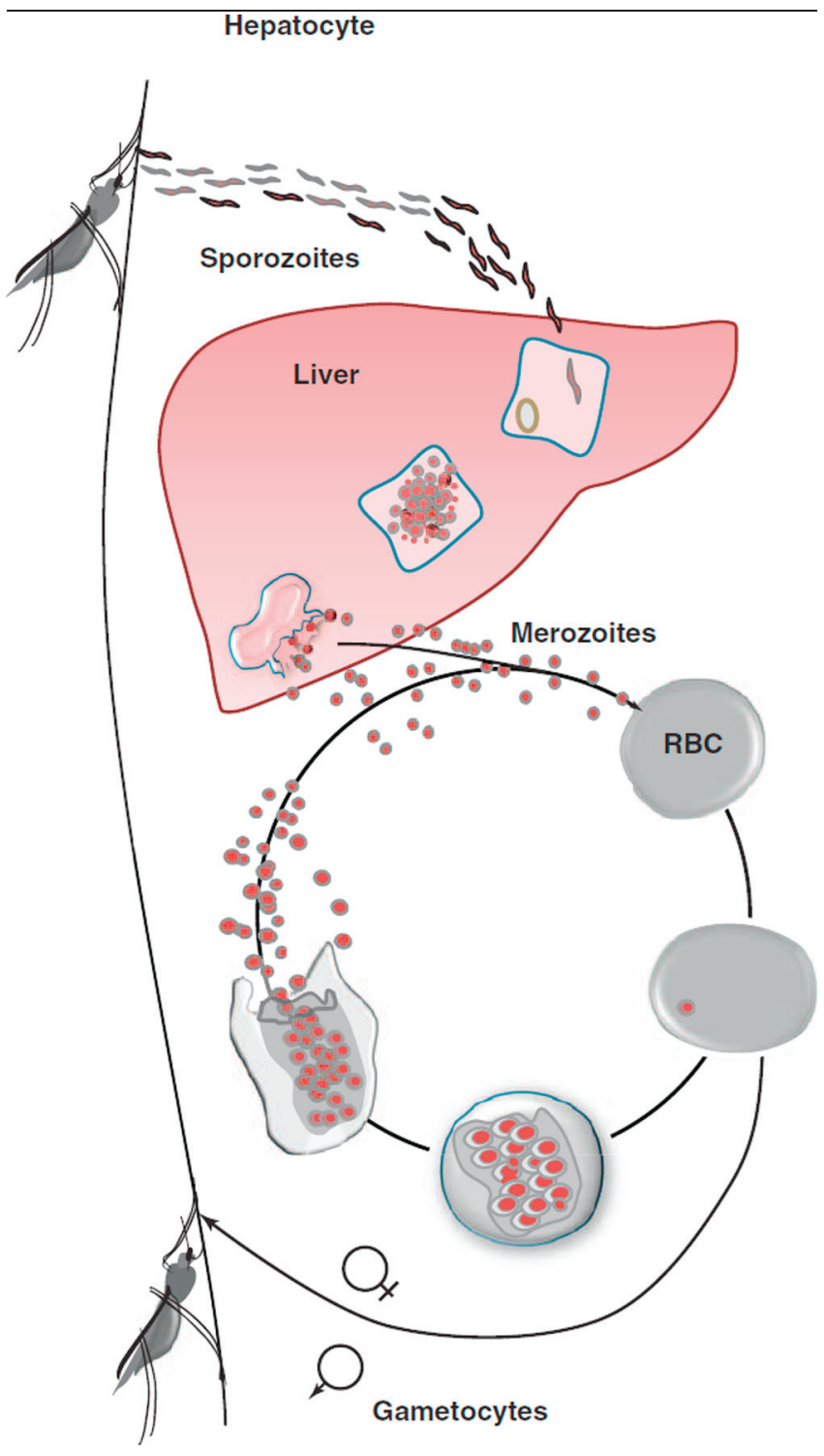

Sporozoites inoculated into skin enter blood vessels and are carried to the liver, where they multiply to form liver stage merozoites. Liver stage merozoites released into the blood stream infect individual host red blood cells to initiate the erythrocytic (blood) stages. Along with the disease-causing asexual blood stage parasites, sexual stages, known as gametocytes, also emerge during blood stage development and serve to transmit the infection to mosquitoes that suck the blood of infected humans. See [69] for a more in-depth summary.

Abbreviations: RBC, red blood cell. Reproduced from Figure I, panel B from http://www.sciencedirect.com/science/article/pii/S I47/4922 I I000353. Figure reproduced with kind permission of authors Robert J. Schwenk and Thomas L. Richie and Trends in Parasitology (copyright license obtained) [69].

stages, when clinical symptoms of malaria occur. Untreated falciparum malaria can rapidly progress to death. Along with the disease-causing asexual blood stage parasites, sexual stages known as gametocytes also emerge during blood stage development [3]. In Plasmodium falciparum, gametocytes appear several days after asexual parasites, whereas $P$. vivax gametocytes can appear at the same time or even before asexual forms in the blood [4].

\section{Malaria drug history}

Quinine and its derivatives

The first pharmaceutical used to treat malaria, quinine, was derived from the tree bark of Cinchona calisaya [5]. Quinine synthesis was first attempted in 1856 by William Henry Perkins, but synthesis was not successful until 1944. Although he failed with quinine, Perkins did succeed in synthesizing "mauve," the first textile dye, thereby launching the synthetic textile dye industry in Germany. Microbiologists adopted these dyes to stain microorganisms, and methylene blue was first found to stain malaria parasites by Paul Erlich. Erlich hypothesized that methylene blue might therefore kill malaria parasites, and together with Paul Guttman successfully treated two malaria patients with this agent [6]. Indeed, methylene blue was the predecessor to both the 4-aminoquinolones and the 8 -aminoquinolones. Chloroquine is perhaps the most important of the 4-aminoquinolones, and other related compounds include the aminophenols amodiaquine and pyronaridine, and the dimeric 4-aminoquinoline, piperaquine. The 8-aminoquinolones including the prototype pamaquine (which was too toxic and so not used for long), primaquine (still in use today as the only licensed drug effective against the dormant liver form, the hypnozoite), and tafenoquine (a drug which is undergoing clinical trials applied as an anti-hypnozoite form treatment). Other derivatives of quinine include the arylamino alcohols mefloquine, halofantrine, and lumefantrine [7]. Parenteral quinine remains an option for the treatment of severe malaria, although parenteral artesunate has shown superior efficacy in recent trials [8]. Both chloroquine and primaquine are synthetic derivatives of quinine, and their development in the mid- $20^{\text {th }}$ century was largely driven by the need to treat soldiers during the world wars $[9,10]$. Each of these drugs, still in use today, probably act by interfering with the parasite's ability to eliminate the toxic by-products of hemoglobin digestion.

\section{Antifolates}

Other drugs have specific enzyme targets in the parasite, such as the antifolates (e.g. sulfadoxine-pyrimethamine), which inhibit the parasite's essential ability to synthesize tetrahydrofolate used for methylation reactions [4]. Antifolates were demonstrated to be effective against malaria as early as the 1930s, and sulfonamide components with better pharmacokinetic profiles and partner drugs were developed over the 1940s and 50s, but antifolates were not generally used for antimalarial treatment until much later owing to the availability of highly effective quinine 
derivatives [6]. Sulfadoxine-pyrimethamine became available in 1971 as second-line therapy for malaria, with resistance developing not long thereafter [11]. Indeed, resistance to antifolate drugs, for which there is a specific enzyme target, evolved more rapidly than resistance to chloroquine [4].

\section{Artemisinin combination therapy}

Unfortunately, the malaria parasite has developed resistance to all the above drugs in different parts of the world. In response to this, WHO recommended artemisinin combination therapy in recent years.

Artemisinin, a derivative of sweet wormwood, Artemisia апnua, is a potent drug that rapidly reduces blood stage parasites, allowing prompt resolution of illness, and was initially developed in 1972 by the Chinese during the Vietnam War. Ho Chi Minh personally asked Mao Zedong for assistance with antimalarials, as North Vietnamese soldiers were dying from malaria at a higher rate than from armed conflicts [12]. Artemisinin combination therapy represented a shift away from monotherapy for malaria, which was common previously. Since artemisinin and its derivatives have very short halflives, a second drug with longer half-life is used in combination to complete the clearance of parasitemia, and the combination of drugs has the additional benefit to forestall the development of resistance. In Cambodia, parasite sensitivity to artemisinin may already be decreasing [13]. In response to this alarming pattern, WHO has formulated a Global Plan for Artemisinin Resistance Containment (GPARC) to address the need for specific and immediate actions to limit spread [14]. Several candidate genes have been proposed to be important in the development of artemisinin resistance [15], but this remains a key ongoing area of research.

\section{Complexities of treatment: stages and species}

\section{Species}

Five species of the malaria parasite, Plasmodium spp., infect humans, with $P$. falciparum causing the most mortality worldwide and $P$. vivax causing significant morbidity. P. vivax, a major contributor to malaria-related morbidity, is more common in areas of lower transmission intensity, and therefore relapses originating from P. vivax dormant form hypnozoites in the liver may be an important contributor to disease incidence [16]. $P$. ovale and Plasmodium malariae are agents of the socalled "benign malarias," and like P.vivax, P. ovale can cause relapsing infections. P. malariae can persist as a blood stage parasite at very low levels and flare up decades after initial infection. Morphologically, P. malariae has been confused on bloodsmear with the recently identified zoonosis, Plasmodium knowlesi, which has a shorter life-cycle of replication than any of the other human malarias, and can cause rapidly progressive and fatal disease if not treated promptly [17].

\section{Stages}

Currently available antimalarials mainly target the symptomatic asexual blood stages, in order to be useful for treatment as earlier stages of infection are clinically silent. In keeping with this, the growth inhibition assay for asexual blood stage $P$. falciparum is the primary screening tool used for candidate antimalarials [4, 1822]. Consequently, although drugs against the dormant hypnozoites and transmissible gametocytes are needed for elimination programs, such drugs are difficult to identify and test, and the drugs used against asexual stages are generally ineffective for these other stages [5]. The only currently available drug which can kill the dormant form hypnozoite and the gametocyte is primaquine, but primaquine cannot be used in patients with glucose-6-phosphate dehydrogenase (G6PD) deficiency or in pregnant women.

Another problem is that lack of standardized assays which could be used to test drugs against dormant form hypnozoites [23] limits drug development for this indication. Rodent models allow screening of blood stage drugs, but rodent parasites do not form hypnozoites [24]. The relapsing Plasmodium cynomolgi model in non-human primates was used in the development of primaquine, but primate models are expensive, low throughput, and not available in many malaria research centers. In vitro models of liver stage infection also have many limitations, including difficulty obtaining sporozoites and low infection rates. Whether cultured hepatocytes retain their in vivo architecture, metabolism, or receptors is an additional concern [25]. On top of this, dormant hypnozoite forms are difficult to distinguish from the early liver exoerythrocytic forms. Despite these obstacles, progress is being made in the development of liver stage hypnozoite assays, albeit none of these appear amenable to high throughput capability that would support clinical drug development [26-28].

Identification of drugs with anti-gametocyte and transmission-blocking effects would aid in eradication efforts. Although artemisinin and its derivatives have been shown to reduce carriage of gametocytes, they do not prevent transmission of mature gametocytes already present at the time of treatment [32-34]. Indeed, the only drug officially recommended by WHO to eliminate gametocytes is primaquine for P. falciparum [8], and encouragingly primaquine has been recently shown to reduce transmission when added to an artemisinin combination therapy in an open-label, randomized trial [32]. 
There are specific assays to screen the effect of drugs on sexual stage parasites and parasite transmission to mosquitoes are available in select centers $[29,31]$.

\section{Overcoming resistance}

Drug resistant parasites typically develop when drugs are at subtherapeutic levels, and therefore the short half-life of artemisinins may protect this class of drugs [19,35]. In addition, pairing the artemisinin derivative with other antimalarial drugs with dissimilar mechanisms of action will delay the emergence of drug resistant parasites. However, because outpatient therapy now relies on this single class of antimalarials, the artemisinins, all of the artemisinin combination therapies will become vulnerable to failure once fully artemisinin-resistant parasites develop and spread. It is not clear whether the synthetic artemisinin analogues currently under early stage development will still be useful if and when this happens.

\section{Something new: new drug candidates}

The good news on the antimalarial development front is that scientific and technological advances will allow for more rapid identification of effective therapy and new targets.

The sequencing of various Plasmodium genomes $[36,37]$ has accelerated target identification and expression analysis. Orthologues (genes that evolved from a common ancestral gene in different species that generally retain the same function) for targets of interest can be easily identified and small molecules against these targets tested in vivo (animal models) or in vitro. High throughput screening in vitro can identify active molecules that can be further optimized for preclinical testing [38]. The molecular-based search for targets is referred to as the "rational design approach." This approach has not yet delivered a product, in part because the time from molecular target identification to clinic testing is great. One problem with this approach is that it favors identification of drugs with one rather than multiple targets, making these more likely to induce parasite resistance.

Others have advocated the "whole parasite screening" approach: molecules are selected from available chemical data, and hits (molecules) are identified through high throughput screening with whole parasites. Molecular targets are then established by generating mutant parasites that are resistant to the active or "hit" molecule. If a particular antimalarial has many targets, it has a lower chance of encountering resistant parasites. This method recently resulted in the identification of a new candidate antimalarial, the spiroindolone NITD609, by Rottman et al. [39], which has been shown to be safe for testing in humans [40].
Mass screening of chemical libraries has yielded a wealth of potential antimalarial compounds, and many are active at sub-micromolar concentrations with minimal toxicity to human cell lines. Screening assays in 1536well formats exist for asexual blood stage P. falciparum, and assays are under development for the dormant liver hypnozoite and transmission stages. In a screen of 2816 registered or approved compounds, 32 compounds were recently found to be active against 45 parasite lines sourced from around the world with IC50 values $\leq 1 \mu \mathrm{M}$, including 10 compounds not previously known to have anti-malarial activity. Genome-wide association and linkage analysis then identified compounds that had similar or distinct mechanisms of action, which might predict cross-resistance and therefore guide combination therapy [41].

To manage such large quantities of data being generated by different groups, a centralized database of high throughput screening results to "facilitate assimilation, integration, and mining of data" has been started by the WHO, the United Nations, and the World Banksponsored Tropical Disease Research group. Also, public-private partnerships and non-profit organizations, such as Medicines for Malaria Venture, Drugs for Neglected Diseases Initiative (DNDi), and African Network for Drugs and Diagnostics Innovation (ANDI), have been developed with the idea of maximizing collaborations and developing new therapies [4].

\section{The current pipeline}

Medicines for Malaria Venture, a non-profit group that supports scientists and companies to develop new antimalarials, highlights a number of compounds considered leads in optimization, as well as antimalarials in the pipeline (preclinical through Phase IV development) on their website, (http://www.mmv.org/researchdevelopment?gclid=CJPY-7e96oCFWUTNAod80I-Pg). Many of these compounds are newly identified or novel in their application to antimalarial therapy.

The initial approach to tackling drug resistance was to develop drugs based on structures of existing antimalarials, and this has been a profitable endeavor. Antimalarials developed based on chloroquine include lumefantrine, piperaquine and pyronaridine developed in China, each of which are now components of artemisinin combination therapys in use or in advanced trial stages. In the United States, other chloroquine-like antimalarials include amodiaquine (also used in artemisinin combination therapy), mefloquine, and halofantrine, although the last of these is not widely used clinically today [4]. Drugs with indirect or direct disruption of pyrimidine metabolism (e.g. pyrimethamine, sulfonamides, atovaquone) 
have inspired the development of new drugs targeting another aspect of the pyrimidine pathway: dihydroorotate dehydrogenase [42]. Some of the lead candidates based on already successful antimalarials [40] are highlighted below:

\section{4-Aminoquinolone derivatives}

Pyronaridine, a chloroquine relative, is being used in combination with artesunate as a promising new artemisinin-based combination therapy. Pyronaridineartesunate has been studied in Phase II and Phase III clinical trials, and has been shown to be effective against uncomplicated $P$. falciparum and blood stage P. vivax [43]. As increasingly chloroquine-resistant strains of $P$. vivax emerge, and as the need to treat $P$. falciparum and $P$. vivax co-infection expands in certain areas, such a regimen is welcome. Pyronaridine-artesunate is available as Pyramax $^{\circledR}$ tablets and pediatric granule formulations, and manufacture of this compound is being undertaken by Shin Poong Pharmaceuticals [40].

\section{8-Aminoquinolone derivatives}

Tafenoquine is a lead candidate drug aimed at a radical cure of $P$. vivax (i.e. elimination of dormant stage hypnozoites), and is being studied in a Phase II/III tafenoquine/chloroquine combination study this year [40]. A fixed dose artemisinin combination therapy, artesunate-amodiaquine (Coarsucam/ASAQ, Winthrop) has been approved by WHO and developed by SanofiAventis and the DNDi, and is undergoing Phase IV field assessment [40].

\section{Artemisinin derivatives}

The endoperoxide feature of artemisinins, which confers antimalarial activity, is shared by ozonide OZ439, a synthetic endoperoxide. OZ439 carries the hope of providing a single dose oral cure in humans when used in combination. OZ439 is a rapidly acting agent against asexual stage parasites, and will likely be developed for use in combination with a partner drug with a longer half-life than its own. Studies are underway to identify such a partner. This drug is currently undergoing Phase IIa trials. [44]

\section{Caveats}

For all of these drugs, the caveats regarding antimalarial resistance and ease of dosing and administration remain. Pharmacokinetic trials in adults, once done, must be followed by appropriate pharmacokinetic studies in children, as it is well known that certain antimalarials (such as piperaquine and sulfadoxine-pyrimethamine) have differing pharmacokinetics in children compared with adults, which will modify their efficacy [45]. Drug efficacy is also influenced by the degree of pre-existing antimalarial immunity, acquired as children get older and are exposed to malaria over and over again [46]. Thus, drug efficacy must be evaluated in children and must take into account these additional factors.

\section{Something old: novel approaches with existing antimalarials \\ Drug cycling}

Re-introduction of drugs after a period of non-use has been considered as a strategy to combat malaria. In Malawi, which halted chloroquine use in 1993 due to resistance, chloroquine was demonstrated to have 99\% clinical efficacy a decade later, presumably due to the re-expansion of susceptible parasites [47, 48]. However, in time it is likely that the re-introduction of drug pressure will likely result in re-emergence of chloroquine-resistant parasites. One way to delay this would be to pair the re-cycled drug with another drug. Combinations of quinine derivatives with antimicrobials have shown synergy, for example chloroquine/azithromycin (which has the advantage that it is safe for children and pregnant women). Clinical studies are underway to assess this combination for use as intermittent preventative treatment, (administration at defined intervals regardless of whether the patient has malaria parasites in the blood, is recommended for pregnant women and infants designed to provide prophylaxis against malaria $[40,49])$.

\section{Getting round resistance}

Preventing resistance in the first place is the major focus of antimalarial drug development today. Artemisinin combination therapies represent a change in antimalarial therapy paradigms since most drugs had been given as a monotherapy in the past. Indeed the use of artesunate monotherapy might have contributed to the development of artemisinin-resistant parasites recently reported in Western Cambodia [13]. In the present and future, combination therapy will enhance efficacy of individual antimalarials and reduce the likelihood of developing resistance.

In addition, agents that reverse resistance to existing antimalarials might extend the useful lifetime of old drugs. Many compounds, including various calcium channel blockers and chlorpheniramine, and even primaquine, as examples, have been shown to reverse chloroquine resistance. However, this approach is not completely straightforward. Drug metabolism, drug levels required to achieve the therapeutic effect, and the lack of clinical research in this area, all represent obstacles to translate this approach into practice [50]. Interestingly, parasites that develop high-grade resistance mutations to antifolates, such as pyrimethamine, might actually be rendered more sensitive to certain novel inhibitors of antifolate metabolism, such as WR99210 [51]. 


\section{Infection-treatment-vaccination}

A novel area of malaria research involves examining the unforeseen benefits of treatment in the development of malaria-specific immunity. In experimental human infection models, complete protection against infection has been induced when patients are repeatedly exposed to infection while taking antimalarials [52]. This form of immunity was found to endure for 2 years or more in some individuals [53], making this an exciting potential approach to malaria prevention. However, testing has thus far been limited to challenge with homologous parasites (the parasite used to vaccinate is the same as that used to challenge volunteers), and therefore future studies will need to examine the degree of immunity induced against heterologous or naturally transmitted parasites.

\section{Something borrowed: novel uses of other anti-infectives}

\section{Drugs used in the management of HIV infection}

HIV protease inhibitors have been shown to have direct anti-parasite effects. Given the geographic overlap between HIV and malaria in sub-Saharan Africa, and evidence that malaria and HIV exert a co-pathogenic effect [2, 54-59], any coincident effect of HIV medications on the malaria parasite would have an obvious benefit. HIV protease inhibitors directly interfere with Plasmodium growth in vitro, in vivo, and ex vivo [7, 60-64]. Clinical studies of this effect are urgently needed, especially since WHO, with few exceptions, does not recommend HIV protease inhibitors for first line antiretroviral regimens.

In addition, HIV protease inhibitors may have chloroquine-resistance reversing properties, according to a patent filed in 2005 [50]. Saquinavir and ritonavir behave synergistically with chloroquine and mefloquine, against chloroquine sensitive and resistant strains of P. falciparum [65]. Various HIV protease inhibitors have also been shown to act synergistically against Plasmodium chabaudi in vivo. $[66,67]$ Synergy might result from HIV protease inhibitors reducing levels of specific enzymes and products (GSH and glutathione) used by the parasite to detoxify by-products of hemoglobin digestion [68].

\section{Conclusions}

The parasite's ability to evolve and adapt to every drug introduced thus far mandates research to identify new targets for antimalarial therapy. New technologies and high throughput approaches are identifying a burgeoning number of drug candidates and novel drug classes with antimalarial activity, however the sobering reality is that only a limited number of antimalarial drugs have emerged from the development pipeline to enter clinical practice over the past century. The Medicines for Malaria
Venture estimates 10-15 years between drug screening and ultimate registration, and thus many of the preclinical antimalarial candidates discussed in this article will not be seen in the clinic in the immediate future. In addition, the call for malaria elimination and eradication is spurring the development of anti-malarials that target the parasite in life cycle stages that were largely ignored by drug developers in the past. In parallel with the effort to develop vaccines that interrupt malaria transmission, the drugs needed to contribute to elimination or eradication will target the parasite during transmission to the mosquito or during its pre-erythrocytic development in the liver, in order to terminate the parasite's spread. All this is a tall order for a drug pipeline that has been historically slow, and hence the need to consider all potential avenues-new, old, or borrowedto revive the malaria armamentarium.

\section{Abbreviations}

DNDi, Drugs for Neglected Diseases Initiative; WHO, World Health Organization.

\section{Competing interests}

The authors declare that they have no competing interests

\section{References}

I. World Malaria Report. World Health Organization (WHO); 2010. [http://www.who.int/malaria/world_malaria_report_2010/ worldmalariareport2010.pdf]

2. Slutsker L, Marston BJ: HIV and malaria: interactions and implications. Curr Opin Infect Dis 2007, 20:3-10.

3. Greenwood BM, Fidock DA, Kyle DE, Kappe SH, Alonso PL, Collins FH, Duffy PE: Malaria: progress, perils, and prospects for eradication. J Clin Invest 2008, I | 8: I266-76.

4. Wells TN, Alonso PL, Gutteridge WE: New medicines to improve control and contribute to the eradication of malaria. Nat Rev Drug Discov 2009, 8:879-91.

5. Alonso PL, Bassat Q, Binka F, Brewer T, Chandra R, Culpepper J, Dinglasan R, Duncan K, Duparc S, Fukuda M, Laxminarayan R, MacArthur JR, Magill A, Marzetta C, Milman J, Mutabingwa T, Nosten F, Nwaka S, Nyunt M, Ohrt C, Plowe CV, Pottage J, Price R, Ringwald P, Serazin A, Shanks D, Sinden R, Tanner M, Vial H, Ward SA: A research agenda for malaria eradication: drugs. PLoS Med 20I I, 8: 1000402.

6. Schlitzer M: Malaria chemotherapeutics part I: History of antimalarial drug development, currently used therapeutics, and drugs in clinical development. Chem Med Chem 2007, 2:944-86.

7. Martins TM, Domingos A, Berry C, Wyatt DM: The activity and inhibition of the food vacuole plasmepsin from the rodent malaria parasite Plasmodium chabaudi. Acta Trop 2006, 97:212-8.

8. Guidelines for the Treatment of Malaria. World Health Organization (WHO); 2009. [http://whqlibdoc.who.int/publications/ 2010/9789241547925_eng.pdf]

9. Baird JK: Resurgent malaria at the millennium: control strategies in crisis. Drugs 2000, 59:719-43.

10. Baird JK, Hoffman SL: Primaquine therapy for malaria. Clin Infect Dis 2004, 39: I 336-45.

II. Baird JK: Effectiveness of antimalarial drugs. N Engl J Med 2005, 352: 1565-77. 
12. Efferth T, Romero MR, Wolf DG, Stamminger T, Marin J], Marschall $M$ : The antiviral activities of artemisinin and artesunate. Clin Infect Dis 2008, 47:804-II.

13. Dondorp AM, Nosten F, Yi P, Das D, Phyo AP, Tarning J, Lwin KM, Ariey F, Hanpithakpong W, Lee SJ, Ringwald P, Silamut K, Imwong M, Chotivanich K, Lim P, Herdman T, An SS, Yeung S, Singhasivanon P, Day NP, Lindegardh N, Socheat D, White NJ: Artemisinin resistance in Plasmodium falciparum malaria. $N$ Engl J Med 2009, 36I:455-67.

FI000 Factor 10

Evaluated by Patrick Duffy 20 Oct $201 \mathrm{I}$

14. Global plan for Artemisinin Resistance Containment. World Health Organization (WHO); 20II. [http://www.who.int/malaria/ publications/atoz/978924I500838/en/index.html]

15. Imwong M, Dondorp AM, Nosten F, Yi P, Mungthin M, Hanchana S, Das D, Phyo AP, Lwin KM, Pukrittayakamee S, Lee SJ, Saisung S, Koecharoen K, Nguon C, Day NP, Socheat D, White NJ: Exploring the contribution of candidate genes to artemisinin resistance in Plasmodium falciparum. Antimicrob Agents Chemother 2010, 54:2886-92

16. Guerra CA, Howes RE, Patil AP, Gething PW, Van Boeckel TP, Temperley WH, Kabaria CW, Tatem AJ, Manh BH, Elyazar IR, Baird JK, Snow RW, Hay SI: The international limits and population at risk of Plasmodium vivax transmission in 2009. PLoS Negl Trop Dis 2010, 4:e774.

FI000 Factor 6

Evaluated by Patrick Duffy 20 Oct 2011

17. Lee KS, Divis PC, Zakaria SK, Matusop A, Julin RA, Conway DJ, CoxSingh J, Singh B: Plasmodium knowlesi: reservoir hosts and tracking the emergence in humans and macaques. PLoS Pathog 20II, 7:el0020I5.

18. Baniecki ML, Wirth DF, Clardy J: High-throughput Plasmodium falciparum growth assay for malaria drug discovery. Antimicrob Agents Chemother 2007, 5 1:716-23.

FI000 Factor 10

Evaluated by David Newman 05 Mar 2007, Patrick Duffy 20 Oct 201 I

19. Burrows JN, Chibale K, Wells TN: The state of the art in antimalarial drug discovery and development. Curr Top Med Chem 20II, I I:I226-54.

FI000 Factor 8

Evaluated by Patrick Duffy 20 Oct 2011

20. Gamo FJ, Sanz LM, Vidal J, de Cozar C, Alvarez E, Lavandera JL, Vanderwall DE, Green DV, Kumar V, Hasan S, Brown JR, Peishoff CE, Cardon LR, Garcia-Bustos JF: Thousands of chemical starting points for antimalarial lead identification. Nature 2010, 465:305- 10 .

FI000 Factor 14

Evaluated by Jeffrey Aubé 01 Jun 2010, David Triggle 0I Jun 2010, Patrick Duffy 20 Oct 201I

21. Guiguemde WA, Shelat AA, Bouck D, Duffy S, Crowther G], Davis PH, Smithson DC, Connelly M, Clark J, Zhu F, Jiménez-Díaz MB, Martinez MS, Wilson EB, Tripathi AK, Gut J, Sharlow ER, Bathurst I, EI Mazouni F, Fowble JW, Forquer I, McGinley PL, Castro S, AnguloBarturen I, Ferrer S, Rosenthal PJ, Derisi JL, Sullivan DJ, Lazo JS, Roos DS, Riscoe MK, Phillips MA, Rathod PK, Van Voorhis WC, Avery VM, Guy RK: Chemical genetics of Plasmodium falciparum. Nature 2010, 465:3II-5.

FI000 Factor 10

Evaluated by Jeffrey Aubé 0 I Jun 2010, Patrick Duffy 20 Oct 2011

22. Plouffe D, Brinker A, McNamara C, Henson K, Kato N, Kuhen K, Nagle A, Adrian F, Matzen IT, Anderson P, Nam TG, Gray NS, Chatterjee A, Janes J, Yan SF, Trager R, Caldwell JS, Schultz PG, Zhou $Y$, Winzeler EA: In silico activity profiling reveals the mechanism of action of antimalarials discovered in a highthroughput screen. Proc Natl Acad Sci U S A 2008, 105:9059-64.

FI000 Factor 14

Evaluated by Paul Roepe 03 Jul 2008, Thomas Kodadek 04 Jul 2008, Kim Lewis 07 Jul 2008, Patrick Duffy 20 Oct 201 I

23. Wells TN, Burrows JN, Baird JK: Targeting the hypnozoite reservoir of Plasmodium vivax: the hidden obstacle to malaria elimination. Trends Parasitol 2010, 26:145-5I.

24. Langhorne J, Buffet P, Galinski M, Good M, Harty J, Leroy D, Mota MM, Pasini E, Renia L, Riley E, Stins M, Duffy P: The relevance of non-human primate and rodent malaria models for humans. Malar J 20I I, 10:23.

25. Silvie O, Rubinstein E, Franetich JF, Prenant M, Belnoue E, Renia L, Hannoun L, Eling W, Levy S, Boucheix C, Mazier D: Hepatocyte CD8I is required for Plasmodium falciparum and Plasmodium yoelii sporozoite infectivity. Nat Med 2003, 9:93-6.

FI000 Factor 9

Evaluated by Dominique Soldati I 4 Jan 2003, Patrick Duffy 20 Oct 201 I

26. Chattopadhyay R, Velmurugan S, Chakiath C, Andrews Donkor L, Milhous W, Barnwell JW, Collins WE, Hoffman SL: Establishment of an in vitro assay for assessing the effects of drugs on the liver stages of Plasmodium vivax malaria. PLoS One 20I0, 5:el4275.

FI000 Factor 6

Evaluated by Patrick Duffy 20 Oct 2011

27. Dembele L, Gego A, Zeeman AM, Franetich JF, Silvie O, Rametti A, Le Grand R, Dereuddre-Bosquet N, Sauerwein R, van Gemert G], Vaillant JC, Thomas AW, Snounou G, Kocken CH, Mazier D: Towards an in vitro model of Plasmodium hypnozoites suitable for drug discovery. PLoS One 201 I, 6:el8162

FI000 Factor 6

Evaluated by Patrick Duffy 20 Oct 2011

28. Sattabongkot J, Yimamnuaychoke N, Leelaudomlipi S, Rasameesoraj M, Jenwithisuk R, Coleman RE, Udomsangpetch R, Cui L, Brewer TG: Establishment of a human hepatocyte line that supports in vitro development of the exo-erythrocytic stages of the malaria parasites Plasmodium falciparum and $P$. vivax. Am J Trop Med Hyg 2006, 74:708-I5.

FI000 Factor 6

Evaluated by Patrick Duffy 20 Oct 2011

29. Buchholz K, Burke TA, Williamson KC, Wiegand RC, Wirth DF, Marti M: A high-throughput screen targeting malaria transmission stages opens new avenues for drug development. $J$ Infect Dis 20II, 203:1445-53.

FI000 Factor 6

Evaluated by Patrick Duffy 20 Oct 2011

30. Tanaka TQ, Williamson KC: A malaria gametocytocidal assay using oxidoreduction indicator, alamarBlue. Mol Biochem Parasitol 2011, 177:160-3.

FI000 Factor 6

Evaluated by Patrick Duffy 20 Oct 2011

31. Wells TN, Poll EM: When is enough enough? The need for a robust pipeline of high-quality antimalarials. Discov Med 2010, 9:389-98.

32. Smithuis F, Kyaw MK, Phe O, Win T, Aung PP, Oo AP, Naing AL, Nyo MY, Myint NZ, Imwong M, Ashley E, Lee SJ, White NJ: Effectiveness of five artemisinin combination regimens with or without primaquine in uncomplicated falciparum malaria: an open-label randomised trial. Lancet Infect Dis 2010, 10:673-8I.

FI000 Factor 6 Evaluated by Patrick Duffy 20 Oct 2011

33. Bousema JT, Schneider P, Gouagna LC, Drakeley CJ, Tostmann A, Houben R, Githure JI, Ord R, Sutherland CJ, Omar SA, Sauerwein RW: Moderate effect of artemisinin-based 
combination therapy on transmission of Plasmodium falciparum. J Infect Dis 2006, 193:II5I-9.

\section{FI000 Factor 6}

Evaluated by Patrick Duffy 20 Oct 2011

34. Price RN, Nosten F, Luxemburger C, ter Kuile FO, Paiphun L, Chongsuphajaisiddhi T, White NJ: Effects of artemisinin derivatives on malaria transmissibility. Lancet 1996, 347:I654-8.

FI000 Factor 6

Evaluated by Patrick Duffy 20 Oct 201 I

35. White N: Antimalarial drug resistance and combination chemotherapy. Philos Trans $R$ Soc Lond B Biol Sci 1999, 354:739-49.

36. Carlton JM, Adams JH, Silva JC, Bidwell SL, Lorenzi H, Caler E, Crabtree J, Angiuoli SV, Merino EF, Amedeo P, Cheng Q, Coulson RM, Crabb BS, Del Portillo HA, Essien K, Feldblyum TV, Fernandez-Becerra C, Gilson PR, Gueye AH, Guo X, Kang'a S, Kooij TW, Korsinczky M, Meyer EV, Nene V, Paulsen I, White O, Ralph SA, Ren Q, Sargeant T], Salzberg SL, Stoeckert CJ, Sullivan SA, Yamamoto MM, Hoffman SL, Wortman JR, Gardner MJ, Galinski MR, Barnwell JW, Fraser-Liggett CM: Comparative genomics of the neglected human malaria parasite Plasmodium vivax. Nature 2008, 455:757-63.

FI000 Factor 10

Evaluated by Frank Seeber 21 Oct 2008, Patrick Duffy 20 Oct 201 I

37. Gardner MJ, Hall N, Fung E, White O, Berriman M, Hyman RW, Carlton JM, Pain A, Nelson KE, Bowman S, Bowman S, Paulsen IT, James K, Eisen JA, Rutherford K, Salzberg SL, Craig A, Kyes S, Chan MS, Nene V, Shallom SJ, Suh B, Peterson J, Angiuoli S, Pertea M, Allen J, Selengut J, Haft D, Mather MW, Vaidya AB, Martin DM, Fairlamb $A H$, Fraunholz MJ, Roos DS, Ralph SA, McFadden GI, Cummings LM, Subramanian GM, Mungall C, Venter JC, Carucci DJ, Hoffman SL, Newbold C, Davis RW, Fraser CM, Barrell B: Genome sequence of the human malaria parasite Plasmodium falciparum. Nature 2002, $419: 498-5$ II.

FI000 Factor 10

Evaluated by Carol Sibley 16 Oct 2002, Patrick Duffy 20 Oct 201 I

38. Wells TN: Microbiology. Is the tide turning for new malaria medicines? Science 2010, 329: II53-4.

39. Rottmann M, McNamara C, Yeung BK, Lee MC, Zou B, Russell B, Seitz P, Plouffe DM, Dharia NV, Tan J, Cohen SB, Spencer KR, González-Páez GE, Lakshminarayana SB, Goh A, Suwanarusk R, Jegla T, Schmitt EK, Beck HP, Brun R, Nosten F, Renia L, Dartois V, Keller TH, Fidock DA, Winzeler EA, Diagana TT: Spiroindolones, a potent compound class for the treatment of malaria. Science 2010, 329: $1175-80$.

FI000 Factor 13

Evaluated by Matthew Bogyo 13 Sep 2010, Karin Romisch 14 Oct 2010, Dominique Soldati 02 Dec 2010, David Triggle 09 Dec 2010, Patrick Duffy 20 Oct 2011

40. Medicines for Malaria Venture. [http://www.mmv.org/]

41. Yuan J, Cheng KC, Johnson RL, Huang R, Pattaradilokrat S, Liu A, Guha R, Fidock DA, Inglese J, Wellems TE, Austin CP, Su XZ: Chemical genomic profiling for antimalarial therapies, response signatures, and molecular targets. Science 2011, 333:724-9.

FI000 Factor 13

Evaluated by Marilyn Parsons 02 Sep 201I, David Triggle 20 Sep 201 I, Patrick Duffy 20 Oct 2011

42. Phillips MA, Rathod PK: Plasmodium dihydroorotate dehydrogenase: a promising target for novel anti-malarial chemotherapy. Infect Disord Drug Targets 20 10, 10:226-39.

43. Kurth F, Belard S, Basra A, Ramharter M: Pyronaridine: a new 'old' drug on the verge of entering the antimalarial armamentarium. Expert Rev Anti Infect Ther 20II, 9:393-6.

FI000 Factor 6

Evaluated by Patrick Duffy 20 Oct 201 I
44. Charman SA, Arbe-Barnes S, Bathurst IC, Brun R, Campbell M, Charman WN, Chiu FC, Chollet J, Craft JC, Creek DJ, Dong Y, Matile H, Maurer M, Morizzi J, Nguyen T, Papastogiannidis P, Scheurer C, Shackleford DM, Sriraghavan K, Stingelin L, Tang Y, Urwyler H, Wang X, White KL, Wittlin S, Zhou L, Vennerstrom JL: Synthetic ozonide drug candidate OZ439 offers new hope for a single-dose cure of uncomplicated malaria. Proc Natl Acad Sci U S A 20I I, 108:4400-5.

FI000 Factor 10

Evaluated by Wesley Van Voorhis 14 Jul 201I, Patrick Duffy 20 Oct 2011

45. Nosten FH: Pyronaridine-artesunate for uncomplicated falciparum malaria. Lancet 2010, 375:14I3-4.

46. Rogerson SJ, Wijesinghe RS, Meshnick SR: Host immunity as a determinant of treatment outcome in Plasmodium falciparum malaria. Lancet Infect Dis 2010, 10:51-9.

47. Laufer MK, Takala-Harrison S, Dzinjalamala FK, Stine OC, Taylor TE, Plowe CV: Return of chloroquine-susceptible falciparum malaria in Malawi was a reexpansion of diverse susceptible parasites. J Infect Dis 2010, 202:801-8.

FI000 Factor 8

Evaluated by Patrick Duffy 20 Oct 201

48. Laufer MK, Thesing PC, Eddington ND, Masonga R, Dzinjalamala FK, Takala SL, Taylor TE, Plowe CV: Return of chloroquine antimalarial efficacy in Malawi. N Engl J Med 2006, 355:1959-66.

FI000 Factor 8

Evaluated by Patrick Duffy 20 Oct 2011

49. Chico RM, Pittrof R, Greenwood B, Chandramohan D: Azithromycinchloroquine and the intermittent preventive treatment of malaria in pregnancy. Malar J 2008, 7:255.

50. Egan TJ, Kaschula $\mathrm{CH}$ : Strategies to reverse drug resistance in malaria. Curr Opin Infect Dis 2007, 20:598-604.

5I. Hastings MD, Sibley CH: Pyrimethamine and WR99210 exert opposing selection on dihydrofolate reductase from Plasmodium vivax. Proc Natl Acad Sci U S A 2002, 99:|3|37-4|.

FI000 Factor 8

Evaluated by Patrick Duffy 20 Oct 2011

52. Roestenberg M, McCall M, Hopman J, Wiersma J, Luty AJ, van Gemert GJ, van de Vegte-Bolmer M, van Schaijk B, Teelen K, Arens T, Spaarman L, de Mast Q, Roeffen W, Snounou G, Rénia L, van der Ven A, Hermsen CC, Sauerwein R: Protection against a malaria challenge by sporozoite inoculation. N Engl J Med 2009, 36 I:468-77.

FI000 Factor 8

Evaluated by Patrick Duffy 20 Oct 2011

53. Roestenberg M, Teirlinck AC, McCall MB, Teelen K, Makamdop KN, Wiersma J, Arens T, Beckers P, van Gemert G, van de VegteBolmer M, van der Ven AJ, Luty AJ, Hermsen CC, Sauerwein RW: Long-term protection against malaria after experimental sporozoite inoculation: an open-label follow-up study. Lancet 201।, 377:1770-6.

54. Abu-Raddad LJ, Patnaik P, Kublin JG: Dual infection with HIV and malaria fuels the spread of both diseases in sub-Saharan Africa. Science 2006, 314:|603-6.

FI000 Factor 6

Evaluated by Gabriele Sorci 03 Jan 2007

55. Korenromp EL, Williams BG, de Vlas SJ, Gouws E, Gilks CF, Ghys PD, Nahlen BL: Malaria attributable to the HIV-I epidemic, subSaharan Africa. Emerg Infect Dis 2005, I I: I4I 0-9.

56. Kublin JG, Steketee RW: HIV infection and malaria-understanding the interactions. J Infect Dis 2006, 193:I-3.

57. Laufer MK, van Oosterhout J, Thesing PC, Dzinjalamala FK, Hsi T, Beraho L, Graham SM, Taylor TE, Plowe CV: Malaria treatment efficacy among people living with HIV: the role of host and parasite factors. Am J Trop Med Hyg 2007, 77:627-32. 
58. Van Geertruyden JP, Menten J, Colebunders R, Korenromp E, D'Alessandro U: The impact of HIV-I on the malaria parasite biomass in adults in sub-Saharan Africa contributes to the emergence of antimalarial drug resistance. Malar J 2008, 7:134.

59. Laufer MK, Plowe CV: The Interaction between HIV and malaria in Africa. Curr Infect Dis Rep 2007, 9:47-54.

60. Andrews KT, Fairlie DP, Madala PK, Ray J, Wyatt DM, Hilton PM, Melville LA, Beattie L, Gardiner DL, Reid RC, Stoermer MJ, SkinnerAdams T, Berry C, McCarthy JS: Potencies of human immunodeficiency virus protease inhibitors in vitro against Plasmodium falciparum and in vivo against murine malaria. Antimicrob Agents Chemother 2006, 50:639-48.

FI000 Factor 8

Evaluated by Patrick Duffy 20 Oct 20II

61. Hobbs CV, Voza T, Coppi A, Kirmse B, Marsh K, Borkowsky W, Sinnis P: HIV protease inhibitors inhibit the development of preerythrocytic-stage plasmodium parasites. J Infect Dis 2009, 199:|34-4|.

62. Lek-Uthai U, Suwanarusk R, Ruengweerayut R, Skinner-Adams TS, Nosten F, Gardiner DL, Boonma P, Piera KA, Andrews KT, Machunter B, McCarthy JS, Anstey NM, Price RN, Russell B: Stronger activity of human immunodeficiency virus type $I$ protease inhibitors against clinical isolates of Plasmodium vivax than against those of $\mathbf{P}$. falciparum. Antimicrob Agents Chemother 2008, 52:2435-41.

FI000 Factor 8

Evaluated by Patrick Duffy 20 Oct 201 I

63. Parikh S, Gut J, Istvan E, Goldberg DE, Havlir DV, Rosenthal PJ: Antimalarial activity of human immunodeficiency virus type I protease inhibitors. Antimicrob Agents Chemother 2005, 49:2983-5.

FI000 Factor 8

Evaluated by Patrick Duffy 20 Oct $201 \mathrm{I}$

64. Redmond AM, Skinner-Adams T, Andrews KT, Gardiner DL, Ray J, Kelly M, McCarthy JS: Antimalarial activity of sera from subjects taking HIV protease inhibitors. AIDS 2007, 21:763-5.

FI000 Factor 8

Evaluated by Patrick Duffy 20 Oct 2011

65. Skinner-Adams TS, Andrews KT, Melville L, McCarthy J, Gardiner DL: Synergistic interactions of the antiretroviral protease inhibitors saquinavir and ritonavir with chloroquine and mefloquine against Plasmodium falciparum in vitro. Antimicrob Agents Chemother 2007, 51:759-62.

66. He Z, Qin L, Chen L, Peng N, You J, Chen X: Synergy of human immunodeficiency virus protease inhibitors with chloroquine against Plasmodium falciparum in vitro and Plasmodium chabaudi in vivo. Antimicrob Agents Chemother 2008, 52:2653-6.

67. Li X, He Z, Chen L, Li Y, Li Q, Zhao S, Tao Z, Hu W, Qin L, Chen X: Synergy of the antiretroviral protease inhibitor indinavir and chloroquine against malaria parasites in vitro and in vivo. Parasitol Res 20I I, [Epub ahead of print].

68. He Z, Chen L, You J, Qin L, Chen X: Antiretroviral protease inhibitors potentiate chloroquine antimalarial activity in malaria parasites by regulating intracellular glutathione metabolism. Exp Parasitol 2009, I 23: | 22-7.

FI000 Factor 6 Evaluated by Patrick Duffy 20 Oct 2011

69. Schwenk RJ, Richie TL: Protective immunity to pre-erythrocytic stage malaria. Trends Parasitol 2011, 27:306-14. 